\title{
Correction to: The Covid-19 World: Learning or Downfall
}

\section{Juha Suoranta ${ }^{1}$}

Published online: 6 October 2020

(C) Springer Nature Switzerland AG 2020

\section{Correction to: Postdigital Science and Education https://doi.org/10.1007/s42438-020-00189-2}

The article was published with an error. Everywhere where should be com was replaced by post. Thus, this erratum is presented to fix this error.

The original article has been corrected.

Juha Suoranta

juha.suoranta@tuni.fi

1 Tampere University, Tampere, Finland 